\title{
POLÍTICA ACCOUNTABILITY EDUCACIONAL NO ESTADO DO CEARÁ: REPERCUSSÕES NAS DINÂMICAS PEDAGÓGICAS
}

\author{
Karlane Holanda Araujo \\ Raimundo Hélio Leite \\ Eric Ferdinando Kanai Passon ${ }^{(*)}$
}

A tendência atual da avaliação educacional condiz com a era accountability, em que a preocupação com a qualidade da educação está associada à melhoria do desempenho cognitivo dos alunos, medida pela aplicação de testes avaliativos, e com a responsabilização dos agentes públicos pelos resultados alcançados.

A política accountability, assentada nos conceitos econômicos de mercado, é caracterizada tanto pela divulgação e pela disseminação dos dados de desempenhos escolares, denominada de responsabilização simbólica, low-stakes, quanto pela utilização de mecanismos de incentivos financeiros e competitivos para mobilizar os profissionais da educação na busca pela melhoria da qualidade, chamada de responsabilização forte, high-stakes.

No Brasil, a política de responsabilização atingiu seu ápice em 2005, quando o Ministério da Educação (MEC), através do Instituto Nacional de Estudos e Pesquisas Anísio Teixeira (Inep), implantou o Índice de Desenvolvimento da Educação Básica (Ideb), que está composto por duas variáveis: o fluxo escolar e as médias de desempenho nas avaliações nacionais. Essas médias referem-se ao desempenho no Sistema de Avaliação da Educação Básica (Saeb)1 para os estados e na Prova Brasil2 para os municípios. Conforme Fernandes (2007), atualmente é possível dispor de um valor do indicador para o país como um todo: para cada estado, município e escola.

\footnotetext{
${ }^{(*)}$ Karlane Holanda Araujo. Doutoranda e Mestra em Educação Brasileira, pelo Programa de Pós-Graduação em Educação, da Universidade Federal do Ceará - UFC - Linha de Avaliação Educacional - e especialista em Gestão e Avaliação da Escola Pública pela Universidade Federal de Juiz de Fora (UFJF). Professora do Instituto Federal de Educação do Ceará (IFCE) - Campus Ubajara. E-mail: karlaneufc@ gmail.com.br

Raimundo Hélio Leite. Universidade Federal do Ceará (UFC).

Eric Ferdinando Kanai Passon. Faculdade de Educação da Universidade de São Paulo (FE-USP)- Universidade Ibirapuera - SP.

1“As avaliações do Saeb produzem informações a respeito da realidade educacional brasileira, especificamente, por regiões, redes de ensino pública e privada nos estados e no Distrito Federal, por meio de exame bienal de proficiência, em Matemática e em Língua Portuguesa (leitura), aplicado em amostra de alunos de $4^{\mathrm{a}}$ e $8^{\mathrm{a}}$ séries do ensino fundamental e da $3^{\mathrm{a}}$ série do ensino médio" (INEP, 2011b, s.p.).

2 “Avaliação Nacional do Rendimento Escolar (Anresc), também denominada 'Prova Brasil': trata-se de uma avaliação censitária envolvendo os alunos da $4^{\mathrm{a}}$ série $/ 5^{\circ}$ ano e $8^{\mathrm{a}}$ série $/ 9^{\circ}$ ano do ensino fundamental das escolas públicas das redes municipais, estaduais e federal, com o objetivo de avaliar a qualidade do ensino ministrado nas escolas públicas.
} 
Na educação básica, o Ideb marcou a forma de fazer política educacional, visto que, por intermédio de critérios bem definidos para aferir a qualidade do desempenho escolar, gerou mudanças no trabalho escolar e na responsabilidade de seus agentes pelos resultados alcançados. Inclusive, em âmbito nacional, os resultados da Prova Brasil, atestados no Ideb de cada município, orientam o repasse de recursos, o que também caracteriza um modelo avaliativo da era do accountability.

Embora existam muitas polêmicas e poucos consensos nos estudos brasileiros sobre os possíveis impactos da implantação das políticas de responsabilização, premiação e bonificação dos atores educacionais vinculadas ao desempenho estudantil, existem experiências de responsabilização educacional, através das políticas de altas ou de baixas consequências - highstakes policies e low-stakes policies -, que acreditam que, ao tornar os membros da equipe escolar corresponsáveis pelo desempenho dos discentes, podem contribuir para a melhoria da qualidade do ensino.

Atualmente, temos políticas estaduais e municipais de responsabilização que utilizam os resultados de desempenho para distribuição de "prêmios" às equipes das escolas e aos alunos, com base em índices e médias de proficiências alcançadas, pressionando, cada vez mais, a corrida para o topo no ranking das escolas nota dez.

Exemplo disso é o caso do Estado do Ceará, que incorporou a política de responsabilização high-stakes (forte) na gestão educacional, como se deduz a seguir:

A convicção do estado do Ceará na eficácia dos prêmios como incentivo para os professores tem uma década de história que, para as escolas de ensino regular, começa com a criação do prêmio Escola do Novo Milênio pela Lei 13.203, de fevereiro de 2002. Alterado em 2004, quando o estado institui o Programa de Modernização e Melhoria da Educação Básica e cria o Selo Escola Destaque do Ano, o prêmio continua ininterrupto até 2007. [...] o novo governador dá continuidade às políticas de incentivos ao criar o Índice Municipal de Qualidade Educacional como base para a distribuição dos $25 \%$ do ICMS pertencentes aos municípios e estabelece as bases para a retomada da premiação de escolas em 2008 por meio da Escola Nota 10. (BROOKE; CUNHA, 2011, p. 49).

Participam dessa avaliação as escolas que possuem, no mínimo, 20 alunos matriculados nas séries/anos avaliados, sendo os resultados disponibilizados por escola e por ente federativo" (INEP, 2011a, s.p.). 
O objeto de estudo desta pesquisa é o Prêmio Escola Nota Dez, política de incentivo nos moldes high-stakes, com consequências de alto valor para as escolas e para seus atores educacionais.

O Prêmio Escola Nota $\mathrm{Dez}^{3}$, criado em 2009, que, na condição de política accountability educacional, acontece anualmente, do qual todos os municípios do Estado do Ceará participam mediante os resultados do Sistema Permanente de Avaliação da Educação Básica do Ceará $(\text { Spaece })^{4}$. A cada ano, são 150 escolas premiadas ${ }^{5}$ de $2^{\circ}, 5^{\circ}$ e $9^{\circ}$ anos do ensino fundamental e 150 escolas apoiadas $^{6}$ de $5^{\circ}$ e $9^{\circ}$ anos do ensino fundamental. O valor do prêmio é calculado considerando a per capita por estudante correspondente à multiplicação do número de discentes matriculados na escola.

Vale reiterar que, para o recebimento da premiação, o município deverá atender ao disposto no artigo $2^{\circ}$, parágrafo $4^{\circ}$, da Lei Estadual 15.923/15, que regulamenta:

O município deverá ter um mínimo de $70 \%$ (setenta por cento) de alunos do $2^{\circ}$ ano do Ensino Fundamental de sua rede, situados no nível 'desejável' da escala de alfabetização do Spaece, e 30\% (trinta por cento) dos alunos no nível 'adequado' da escala de Língua Portuguesa e da escala de Matemática do $5^{\circ}$ ano, como condição para que escolas de sua rede possam receber o Prêmio, com exceção do Município de Fortaleza.

Diante desses dados, percebe-se que o Prêmio Escola Nota Dez tem grande repercussão em todo o Estado do Ceará, por envolver seus 184 municípios e abranger a rede pública de ensino, com mais de 5.000 escolas, o qual vem a nove anos balizando as ações pedagógicas voltadas para a educação de crianças. A relevância deste estudo para o campo da ciência da educação, sobretudo para as áreas de ensino, avaliação, gestão e política educacional, justifica-se por analisar os efeitos da política accountability nas dinâmicas pedagógicas das escolas cearenses.

\footnotetext{
${ }^{3}$ O Prêmio Escola Nota Dez atualmente é disciplinado pela Lei 15.923, de 15 de dezembro de 2015, e configura-se no cenário da educação cearense como uma política de gestão pública que mobiliza os municípios, as escolas e os professores a melhorarem a proficiência estudantil de $2^{\circ}, 5^{\circ}$ e $9^{\circ}$ anos do Ensino Fundamental, em Português e em Matemática (CEARÁ,2015).

${ }^{4}$ Avaliação externa em larga escala que avalia as competências e habilidades dos alunos do Ensino Fundamental e do Ensino Médio, em Língua Portuguesa e em Matemática. Foi implementado em 1992 pelo Governo do Estado do Ceará por meio da Secretaria de Educação. (SEDUC, 2008).

${ }^{5}$ Escolas premiadas são as 150 escolas com as melhores médias no Spaece-Alfa (entre 8,5 e 10,0 ) e no Spaece $5^{\circ}$ e $9^{\circ}$ (entre 7,5 e 10,0) (CEARÁ, 2015).

${ }^{6}$ Escolas apoiadas são as 150 escolas com piores médias no Spaece $5^{\circ}$ e no Spaece $9^{\circ}$. Estas recebem contribuição financeira e apoio técnico-pedagógico (CEARÁ, 2015).
} 
No cenário da educação cearense, são raras as produções científicas que se dedicam a estudar especificamente os efeitos das políticas de responsabilização, no caso, os do Prêmio Escola Nota Dez. Entre dois artigos localizados, há um que aborda a Política de incentivos à escola melhora a proficiência no ensino fundamental? Uma avaliação do Prêmio Escola Nota Dez (CARNEIRO; IRFFI, 2014) e outro que contempla O Prêmio Escola Nota Dez: meritocracia e cooperação para melhoria do desempenho escolar (CALDERÓN; RAQUEL; CABRAL, 2015). Ambos investigam as características e os fundamentos do referido prêmio e suas resultantes no desempenho escolar.

Além desses dois artigos, localizamos ainda uma tese, intitulada Política de responsabilização como estratégia para promoção de desempenho escolar: um estudo sobre o Prêmio "Escola Nota Dez”, de autoria de Luisa Xavier de Oliveira, publicada na Universidade Federal do Rio de Janeiro (UFRJ) em 15 de julho 2016, que teve como orientadora a professora doutora Mariane Campelo Koslinski, estudiosa da temática da política de responsabilização no Brasil.

Percebe-se, então, uma carência nesse campo de pesquisa educacional e também uma lacuna por não tratar acerca dos efeitos do Prêmio Escola Nota Dez, como política de responsabilização high-stakes, nas dinâmicas pedagógicas (planejamento, ensino/currículo, avaliação) das escolas premiadas e das escolas apoiadas. Nesse sentido, o objetivo deste estudo concentrou-se em responder a seguinte questão:

Quais as repercussões da política accountability educacional, representada pelo Prêmio Escola Nota Dez nas dinâmicas pedagógicos das escolas premiadas e das escolas apoiadas do Estado do Ceará?

Nossa investigação não se limitou a pesquisar dados secundários e quantitativos, adiantou-se no sentido de investigar o alcance da política accountability, representada pelo Prêmio Escola Nota Dez para o âmbito pedagógico, priorizando a coleta de dados primários e de natureza qualitativa.

Para um melhor discernimento, o presente artigo encontra-se estruturado em cinco seções. $\mathrm{Na}$ primeira parte, veicula-se esta breve introdução. Na segunda parte, apresenta-se a política accountability na versão do Prêmio Escola Nota Dez. Na terceira parte, evidencia-se a metodologia da pesquisa. Na quarta parte, abordam-se, sucintamente, os efeitos do Prêmio Escola Nota Dez nas dinâmicas pedagógicas das escolas premiadas de Sobral e apoiadas de Caucaia no Estado do Ceará. Na quinta e última parte, expõem-se as considerações finais do estudo. 


\section{A POLÍticA ACCOUNTABILITY NA VERSÃO DO PRÊMIO ESCOLA NOTA DEZ}

A política accountability, conforme discrimina Afonso (2009), implica em três variáveis articuláveis entre si: a avaliação, a prestação de contas e a responsabilização dos resultados. No contexto educacional, a avaliação permite o levantamento, o tratamento e a análise de informações acerca da situação de desempenho do distrito, da unidade escolar e do aluno; a prestação de contas viabiliza a produção de relatórios, mapas e rankings para a publicização dos resultados escolares; e a responsabilização é a cobrança legítima atribuída aos educadores pelo aprendizado dos alunos.

No campo educacional brasileiro, o modelo accountability tem balizado as atuais políticas adotadas pelo Estado. Esse fato se justifica dada a valorização das avaliações em larga escala como peça-chave para maior visibilidade e transparência a respeito dos aspectos centrais do processo de aprendizagem, que atribuíram ao Estado o papel de avaliador da eficiência e qualidade educacional.

No Brasil, até meados da década de 1990, não existiam medidas de avaliação da aprendizagem que produzissem evidências sólidas sobre a qualidade dos sistemas de ensino no país, com exceção do sistema de avaliação da pós-graduação, sob a responsabilidade da Coordenação de Aperfeiçoamento de Pessoal de Nível Superior (Capes), as políticas educacionais eram formuladas e implementadas sem qualquer avaliação sistemática (CASTRO, 2009).

A implantação das políticas de responsabilização iniciou-se, em 1990, com a criação do Sistema de Avaliação da Educação Básica (SAEB). O SAEB, em sua concepção original, seria o melhor exemplo da primeira geração, visto que apresentava caráter diagnóstico e a divulgação dos resultados era restrita, portanto não havia impacto significativo para as escolas. (BONAMINO; SOUSA, 2012).

Em 2005, com o surgimento da Prova Brasil, avaliação para verificar o desempenho dos alunos de $5^{\circ}$ e $9^{\circ}$ ano do ensino fundamental, nos componentes de Língua Portuguesa e de Matemática, deu-se início à segunda geração das políticas brasileiras de avaliação. Com a Prova Brasil e com alguns sistemas estaduais de avaliação, os resultados passaram a ser analisados até o âmbito da escola, permitindo a responsabilização dos gestores e dos professores, causando maior exposição das escolas, mas sem atribuição de recompensas ou sanções. (BONAMINO; SOUSA, 2012).

Especificamente na educação básica, a política de responsabilização vai alcançar seu ápice a partir do ano de 2005, quando no processo de expansão do papel da avaliação em larga escala, foi demarcada pela implantação do IDEB, peça-chave do Plano de Desenvolvimento da Educação (PDE) (FERNANDES; GREMAUD, 2009). A partir do IDEB, inicia-se a terceira geração do sistema de avaliação brasileiro, representada por sistemas estaduais e municipais de avaliação que apresentam 
políticas de responsabilização de consequências fortes para os atores educacionais, premiando escolas em função de seus resultados. (ARAÚJO, 2016).

A política de responsabilização associa resultados de aprendizagem a recompensas ou sanções para os atores educacionais. A pressão que a autoridade educacional aplica para induzir o alcance da proficiência desejada pode ser calibrado pelo tipo de consequência, reais ou simbólicas, que é comum rotular de níveis de pressão mais forte de high-stakes e os mais brandos de lowstakes.

Um dos estados precursores na implantação desse modelo de política accountability é o Estado do Ceará, que vem, desde o início dos anos 1990, consolidando a cultura de avaliação e gestão por resultados, com efeitos low-stakes e high-stakes.

Em reconhecimento aos resultados alcançados nas avaliações estaduais no ano de 2002 foi criada a Lei 13.203, de 21 de fevereiro de 2002, designava que o Prêmio Educacional Escola do Novo Milênio (PEENM)-Educação Básica de Qualidade no Ceará deveria ser outorgado aos membros das equipes das 100 melhores escolas, sendo que, para as 50 melhores escolas, o prêmio era de $100 \%$ do valor especificado, para as demais, era de 50\%. Conforme estudo de Araújo (2016), nessa premiação verificam-se tanto consequências low-stakes, pelo uso dos resultados da avaliação para promover o reconhecimento público das escolas, como também há sinais de efeitos highstakes, ao conceder incentivos monetários aos profissionais de educação e premiações aos discentes.

Em 2004, a Lei 13.203 foi revogada pela Lei 13.541, de 22 de novembro de 2004, e instituiu-se o Programa de Modernização e Melhoria da Educação Básica (PMMEB). O PMMEB teve seu percurso até o ano de 2007 e de acordo com a pesquisa de Araújo (2016, p.66), “este prêmio constituía-se como instrumento de gestão por responsabilização nos moldes low-stakes, sua consequência limitava-se ao caráter simbólico mediante a aquisição da certificação e do selo das escolas destaque".

Em 2009, o Estado do Ceará concebeu leis que disciplinam programas, como: o Prêmio Escola Nota Dez, o Plano de Desenvolvimento da Educação (PDE) e o Prêmio Aprender pra Valer. Tais programas estão focados nos resultados escolares, vinculados ao repasse de recursos atrelados ao desempenho dos alunos, premiação por mérito e bonificação como reconhecimento ao cumprimento de metas e melhoria no aprendizado do discente.

O Prêmio Escola Nota Dez faz uso do Sistema Permanente de Avaliação da Educação Básica do Ceará (Spaece) para aferir a eficiência da aprendizagem dos alunos, classificar e premiar. 
Atualmente, a premiação ocorre com base nos resultados das turmas de $2^{\circ}, 5^{\circ}$ e $9^{\circ}$ ano do Ensino Fundamental. Recebe o referido prêmio, as 150 escolas com os melhores resultados no Índice de Desempenho Escolar (IDE-Alfa) entre 8,5 e 10,0 e no Índice de Desempenho Escolar (IDE-5; IDE-9) entre 7,5 e 10,0. O prêmio também oferece aporte financeiro às 150 escolas com os mais baixos desempenhos das turmas de $5^{\circ}$ e $9^{\circ}$ ano do Ensino Fundamental. É condição para a escola ser agraciada com o prêmio, ter no mínimo 20 estudantes matriculados na série em questão, bem como ter pelo menos $90 \%$ destes avaliados. (ARAÚJO, 2016).

O valor da premiação para as 150 melhores escolas é de $\mathrm{R} \$ 2.000$ por aluno, e a contribuição de auxílio financeiro para as 150 escolas de baixo desempenho é de R $\$ 1.000$ per capita por discente. Especialmente para as escolas premiadas, do total dos recursos recebidos, $20 \%$ são atribuídos para a bonificação dos profissionais de educação que colaboraram diretamente para o cumprimento das metas; $70 \%$ devem ser aplicados em obras, pequenas reformas, material didático, ou seja, empregados em recursos físicos e estruturais permanentes; os $10 \%$ restantes destinam-se às visitas técnicas às escolas apoiadas.

Diante desse modelo de premiação, convém destacar que a versão do Prêmio Escola Nota Dez caracteriza-se por ser uma política accountability educacional de alocação de recursos, com base em resultados das avaliações do Spaece, com consequências fortes ou responsabilização highstakes, visto que a distribuição de recursos, condicionada ao melhor desempenho escolar, provoca a competição entre as escolas, a reorientação das práticas pedagógicas e a preleção de conteúdos curriculares de acordo com as matrizes das avaliações externas.

\section{METODOLOGIA}

Em primeiro lugar, faz-se oportuno mencionar que os dados e as análises descritas nesse

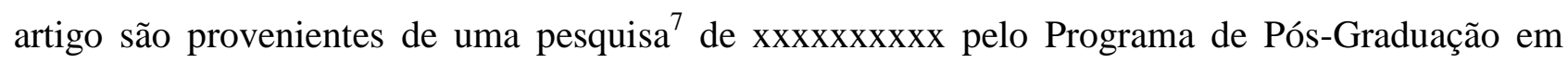

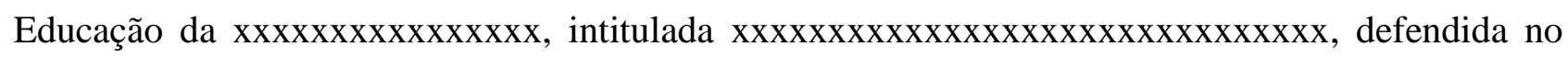
ano de $x x x x$.

A fim de definir a população da pesquisa, fez-se previamente uma consulta documental aos resultados do Prêmio Escola Nota Dez entre o período de sua criação, 2009, até o ano de 2013. Em seguida, decidiu-se por identificar qual o município com maior incidência de premiação por melhor desempenho escolar no Sistema Permanente de Avaliação da Educação Básica do Ceará (Spaece-

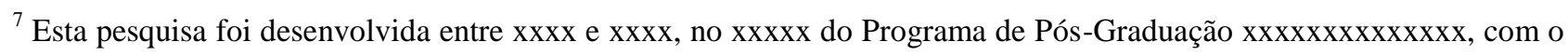

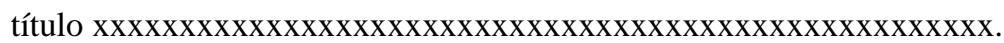


Alfa), como também verificar se, em algum dos eventos executados, existia uma convergência entre o município com mais escolas premiadas e o município de escolas apoiadas.

Mediante esse filtro, detectou-se que a cidade de $\operatorname{Sobral}^{8}$ foi a que obteve maior ocorrência de recebimento do prêmio e que, para surpresa, no ano de 2009, as escolas premiadas desse município haviam apoiado escolas de Caucaia $^{9}$ com menor desempenho na avaliação do Sistema Permanente de Avaliação da Educação Básica do Ceará (Spaece-Alfa). Assim, estabeleceram-se o período da pesquisa e as cidades que seriam investigadas.

Classificou-se, então, o universo da pesquisa em dois estratos: estrato 1, das escolas premiadas (EPs) de Sobral, e estrato 2, das escolas apoiadas (EAs) de Caucaia.

Após a escolha dos municípios, a etapa seguinte foi eleger as instituições de ensino a serem pesquisadas. De um total de 23 escolas premiadas em Sobral no período de 2009, optou-se por duas EPs; uma escola por já ter sido contemplada pelo prêmio três vezes (EP1) e a outra por ter sido agraciada duas vezes (EP2). As EAs definiram-se em decorrência do modelo de cooperação, ficando EA1 e EA2, de acordo com suas respectivas EPs. Vale acrescentar ainda que, em ambos os estratos, constam escolas localizadas tanto na sede como no distrito municipal, a fim de se permitir o confronto entre os diferentes contextos.

Para a coleta de dados, realizaram-se entrevistas semiabertas aos representantes do núcleo gestor escolar, aos professores que atuam nas turmas de $2^{\circ}$ ano do ensino fundamental e aos alunos da série indicada.

Neste escrito, os relatos dos sujeitos da pesquisa estão identificados por meio de monogramas a fim de preservar as identidades dos entrevistados. Para o estrato das escolas premiadas de Sobral, os sujeitos da pesquisa foram identificados pelas abreviaturas " $\mathrm{D}$ ”, para diretor; "P”, para professora; e "A", para aluno, seguido do número que o representa e a sigla da escola (EP1 ou EP2); seguindo esse padrão, os entrevistados das escolas apoiadas de Caucaia foram denominados pelas mesmas abreviaturas, acrescido do número que o representa e da sigla da escola (EA1 ou EA2).

Por ser o estudo de natureza qualitativa, as falas dos participantes da pesquisa foram analisadas com base na hermenêutica gadameriana, especialmente com aplicação da noção de fusão

\footnotetext{
${ }^{8}$ Município cearense com uma população estimada de 205.529 habitantes, situado no semiárido sertão centro-norte do Estado. (Instituto Brasileiro de Geografia e Estatística, 2017).

${ }^{9}$ Município cearense com uma população estimada de 362.233 habitantes, situado na região metropolitana do Estado. (Instituto Brasileiro de Geografia e Estatística, 2017).
} 
de horizontes. Nessa perspectiva, o filósofo Gadamer (1997, p. 327) aponta o caminho, conceituando:

O conceito de horizonte [...], porque ele exprime a elevada amplitude de visão que deve ter quem compreende. Adquirir um horizonte significa aprender sempre a ver além do que está próximo, demasiado próximo, não para afastar o olhar, mas para melhor ver, num conjunto mais vasto e em proporções mais justas.

Por outras palavras, a partir do estabelecimento de uma relação 'dialógica' intersubjetiva nasce a "fusão de horizontes", criada por Gadamer, que é, antes de tudo, compreensões acordadas, considerando-se que "[...] a compreensão é sempre a fusão destes horizontes que supostamente existem por eles mesmos" (GADAMER apud SCHMIDT, 2013, p. 155). Este foi o caminho adotado na análise das entrevistas dos participantes deste estudo.

Trazendo esse pressuposto para o tratamento dos dados, considera-se que o Projeto Escola Nota Dez, objeto deste estudo, vem sendo executado desde o ano de 2009, o que possibilita obter uma visão não imediatista e transitória, mas uma visão mais duradoura das mudanças vivenciadas por diretores, professores e alunos, o que proporcionará visualizar horizontes no decorrer desse período. Especificamente, pretende-se aqui elevar a amplitude de visão de horizontes acerca dos efeitos que o Prêmio Escola Nota Dez vem causando durante esse período de tempo sobre as dinâmicas pedagógicas das escolas premiadas e das escolas apoiadas.

\section{O PRÊMIO ESCOLA NOTA DEZ E SEUS EFEITOS NAS DINÂMICAS PEDAGÓGICAS DAS ESCOLAS PREMIADAS DE SOBRAL E APOIADAS DE CAUCAIA NO ESTADO DO CEARÁ}

Antes da explanação acerca das repercussões pedagógicas do Prêmio Escola Nota Dez, fazse necessário caracterizar as escolas pesquisadas com o propósito de favorecer uma compreensão mais contextualizada dos dados e resultados encontrados.

\section{Caracterização das escolas premiadas e das escolas apoiadas}

As escolas premiadas foram pesquisadas na cidade de Sobral Região Noroeste do Ceará, a 230 quilômetros da capital do estado, Fortaleza. Foram selecionadas duas escolas, tais instituições estão identificadas por escola premiada 1 (EP1) e escola premiada 2 (EP2).

A EP1, localizada na zona urbana de Sobral, oferece as etapas de ensino: educação infantil (creche e pré-escola), ensino fundamental (séries iniciais) e educação de jovens e adultos (EJA). Essa escola foi contemplada com o Prêmio Escola Nota Dez -Spaece-Alfa em três oportunidades, 
nos anos de 2009, 2011 e 2013. Na primeira vez em que essa unidade escolar foi agraciada, apresentava a seguinte indicação de padrão de desempenho: 2,5\% não alfabetizado, 3,7\% alfabetização incompleta, 19,1\% intermediário, 19,1\% suficiente e 55,6\% desejável (CEARÁ, 2015). Já em 2014, a EP1 atingiu 99\% do percentual de seus educandos com padrão de desempenho “desejável” para o processo de alfabetização e alcançou proficiência média ${ }^{10}$ em Língua Portuguesa de 216,2 .

A EP2, também situada em Sobral, localizada no Distrito de Caracará, dispõe dos níveis de ensino da educação infantil (creche e pré-escola), do ensino fundamental (séries iniciais e finais) e da EJA. Essa instituição de ensino foi agraciada com a premiação nos anos de 2009 e 2012 . No primeiro ano de recebimento do prêmio, a referida escola apresentava $97 \%$ dos alunos com padrão de desempenho "desejável" e somente 3\% no padrão de desempenho suficiente. Atualizando esses dados, no ano de 2014, a EP2 obteve 93,9\% dos estudantes por padrão de desempenho "desejável" para o processo de alfabetização e proficiência média em Língua Portuguesa de 207,8, ficando também acima da média estadual (CEARÁ, 2015).

Diante dos resultados aferidos pelo Sistema Permanente de Avaliação Básica do Estado do Ceará (Spaece-Alfa), a EP1 e a EP2 conquistaram, em 2014, respectivamente, IDE-Alfa 10,0 e 9,8, destacando-se no cenário da educação cearense em face da meta de alfabetizar todos os educandos do $2^{\circ}$ ano.

Quanto à pesquisa às escolas apoiadas, realizou-se na cidade de Caucaia, município brasileiro do Estado do Ceará que integra a Região Metropolitana de Fortaleza. Foram selecionadas duas escolas da rede de ensino de Caucaia, que participaram do Prêmio Escola Nota Dez em 2009, na condição de escolas apoiadas, e estabeleceram parcerias com as escolas premiadas de Sobral. Tais instituições estão identificadas por escola apoiada 1 (EA1) e escola apoiada 2 (EA2).

A EA1 oferece educação infantil (creche e pré-escola) e ensino fundamental (séries iniciais). A EA1, quando selecionada para ser escola apoiada, tinha padrão de desempenho de alfabetização incompleta. Verificou-se que, em 2009, a concentração maior de alunos do $2^{\circ}$ ano do ensino fundamental era no padrão de desempenho não alfabetizado e alfabetização incompleta do SpaeceAlfa, totalizando $65,3 \%$. Somente $8,2 \%$ dos discentes obtiveram resultado de desempenho desejável. No ano seguinte, o quadro apresentou mudanças significativas, o padrão de desempenho

\footnotetext{
10 "Aqueles que se encontram no intervalo de 200 a 225 pontos da Escala de Proficiência ampliam suas estratégias de leitura, quanto às habilidades de identificar o gênero e a finalidade de textos diversos, a partir da resolução de tarefas que apresentam textos com vocabulário complexo. Localizam informações explícitas em um texto verbal longo, de forma literal ou parafraseada, e inferem no sentido de palavra ou expressão." (CEARÁ, 2013c, p. 46, grifo do autor).
} 
suficiente cresceu de $8,2 \%$ para $26 \%$ e o de desempenho desejável aumentou de 8,2\% para $18 \%$, concentrando, portanto, $70 \%$ dos educandos nos níveis intermediário, suficiente e desejável.

Atualizando os dados de desempenho no Spaece-Alfa, a EA1, em 2014, obteve 3,3\% dos aprendizes de $2^{\circ}$ ano do ensino fundamental não alfabetizados; $11 \%$, alfabetização incompleta; 18,7\%, intermediário; 18,7\%, suficiente; e 48,4\%, desejável. Com efeito, a indicação de padrão de desempenho foi suficiente (CEARÁ, 2015).

A outra escola de Caucaia pesquisada, a EA2, oferece os níveis de ensino de educação infantil (creche e pré-escola) e de ensino fundamental (séries iniciais). Observou-se que a EA2, no ano de 2009, apresentou indicação de padrão de desempenho alfabetização incompleta, já posteriormente, em 2010, ascendeu para o padrão de desempenho suficiente. Notou-se que houve uma melhoria significativa nos resultados do Spaece-Alfa, visto que, em 2009, a EA2 alcançou apenas 8,6\% dos alunos no padrão de desempenho desejável e que, em 2010, esse percentual subiu para 46,9\%. Isso demonstra, portanto, melhores resultados na proficiência desejável, representada pela cor verde-escura, atestando que o aprendiz desenvolveu habilidades de leitura.

Em 2014, a indicação do padrão de desempenho no Spaece-Alfa permaneceu suficiente, com 50\% dos educandos no padrão desejável; 17,9\%, no suficiente; 17,9\%, no intermediário; e 14,3\%, na alfabetização incompleta. Embora a EA2 tenha melhorado seus resultados no SpaeceAlfa, percebe-se que ainda existem discentes com nível de alfabetização incompleta.

Mediante os resultados aferidos pelo Spaece-Alfa, é possível identificar que, a partir de 2009, período em que a EA1 e a EA2 participaram do Prêmio Escola Nota Dez na condição de escolas apoiadas, recebendo cooperação técnica e pedagógica das escolas premiadas de Sobral, estas começaram a apresentar crescimento nas proficiências de competências de alfabetização.

\section{Resultantes do Prêmio Escola Nota Dez nos componentes pedagógicos: planejamento, ensino e avaliação.}

Percebe-se que é expressivo o movimento ascendente das médias de proficiências em nível “desejável” nos municípios cearenses pesquisados. As habilidades e competências de alfabetização, segundo a Seduc, vêm evoluindo significativamente em todo o estado, em 2007, o percentual de alunos alfabetizados era de 29,9\%, em 2010, ascendeu para 54,9\%, em 2013, permaneceu evoluindo, atingindo 61,2\% de crianças com nível “desejável” e, em 2016 atingiu 74,9\%. (CEARÁ, 2016). 
Esses dados revelam um avanço aligeirado a favor do padrão de qualidade estabelecido pelas políticas educacionais, os quais indicaram de avanço "verde", devido à cor que representa quando o aprendiz desenvolve habilidades “desejáveis” próprias de um leitor.

No mapa da alfabetização das crianças cearenses, o avanço "verde" não está associado estritamente à cultura de avaliação que foi empreendida pelo Programa de Alfabetização na Idade Certa (Paic) ${ }^{11}$, mas, sobretudo, ao modelo de gestão por resultados do Prêmio Escola Nota Dez, que faz frente para impulsionar e alavancar as melhorias no padrão de desempenho da alfabetização na idade certa.

$\mathrm{Na}$ tentativa de ampliarmos novos achados, para além desses dados secundários aferidos dos resultados produzidos pelos sistemas de avaliação externa estadual, a pesquisa desvelou as repercussões do Prêmio Escola Nota Dez nas ações pedagógicas das escolas premiadas de Sobral e das escolas apoiadas de Caucaia, possibilitando-nos imprimir uma nova visão acerca das resultantes da política accountability no cenário da educação cearense.

O presente estudo indica os efeitos desse modelo de política nas dinâmicas pedagógicas (planejamento, ensino e avaliação).

Por exemplo, no componente pedagógico planejamento, os diretores das escolas cearenses pesquisadas afirmaram que:

O planejamento da escola é quinzenal. Uma vez por mês, os professores têm um dia inteiro de formação em Sobral, com todas as professoras do $2^{\circ}$ ano; tem as formadoras. É onde elas estudam o programa, quando elas chegam nos planejamentos daqui, elas revisam e vão implementando de acordo com a realidade, porque a gente faz adequações.[...] O que a gente faz, a gente segue as orientações da secretaria, eles já passam para a gente o material que disponibilizam nas formações para os professores. É claro que para isso tem que seguir o currículo. (DEP1).

O planejamento quinzenal acontece na própria escola, cada professor faz o seu plano de aula buscando atender as necessidades da turma e das exigências da matriz curricular do Spaece-Alfa. (DEA1).

Verificou-se que, embora os dois estratos de escolas tenham como meta planejar ações voltadas para o Spaece-Alfa, as instituições premiadas realizam o planejamento em rede de ensino e na própria escola, de forma sistematizada, com acompanhamento de formadores e de

\footnotetext{
11 “[...] programa do Governo Federal que tem como objetivo garantir que todas as crianças estejam alfabetizadas até os oito anos de idade, ao final do $3^{\circ}$ ano do ensino fundamental” (NETO, 2014, p.191).
} 
coordenadores, fazendo as adequações necessárias, bem diferente do planejamento das escolas apoiadas que realizam planejamento individual uma vez por semana na própria instituição. Em face disso, consoante Freitas (2014), o professor e a escola tendem a eleger nos planejamentos, conteúdos e métodos de trabalho mais propícios à lógica da política educacional vigente.

Ainda no componente planejamento, mas voltado ao currículo escolar, os dois estratos de escolas seguem as orientações da matriz de referência do Spaece-Alfa para selecionar os conteúdos programáticos, como confirmam as professoras a seguir:

A gente trabalha os descritores de três formas, primeiro, na questão da leitura, a gente trabalha os gêneros, todos os descritores na questão da leitura, com cartazes, com trabalho em equipe com as crianças. [...] Depois vem a atividade do projeto, que é esse do aprender, que aborda e trabalha todos os descritores do Spaece, só que de uma forma bem interdisciplinar [...].Cada um olha, vê no diagnóstico o descritor que apresenta mais erro, em que as crianças têm mais dificuldade, aí, em cima daquele erro, em cima daquela questão, a gente planeja e faz essas atividades [...]. (P5EP2).

O professor vai trabalhando as matérias e, ao mesmo tempo, alfabetizando (letramento). Letramento porque trabalha a leitura e a interpretação, o livro tem muitas gravuras [...], trabalha a compreensão do que o aluno leu. Esse livro é uma aquisição do município, Coleção Caminhos. Tem ainda uns cartazes ilustrativos dos temas trabalhados[...]. O pessoal da editora dá capacitação por mês nas escolas. [...] eu percebo que esse material tem relação com os descritores do Spaece. É um bom material, ajuda bastante, só o livro do PNLD é vago, falta uma coisa a mais, esse material da Coleção Caminhos é bem dinâmico. (P1EA1).

Observou-se que as unidades premiadas realizam diagnósticos dos alunos a fim de identificar as dificuldades de leitura e de escrita. A partir daí, trabalham os descritores do SpaeceAlfa com atividades diversificadas, implementando os ajustes necessários à realidade de aprendizagem das crianças. As instituições apoiadas fazem uso de um material didático complementar, que trabalha os descritores do Spaece-Alfa, mas centrando-se na preparação de atividades e de testes nos moldes da prova do Spaece-Alfa, sem uma adequação às necessidades do alunado. Essa constatação reforça os pressupostos de Freitas (2014) e Neto (2014) de que as avaliações externas tendem a comprimir e a moldar o currículo escolar à matriz de referencia dos testes, restringindo, assim o direito de aprender do educando ao básico para atender às exigências dos processos produtivos sociais. 
$\mathrm{Na}$ dinâmica que envolve o ensino, captou-se que os dois estratos dizem trabalhar a alfabetização e o letramento das crianças; vejamos o que disseram as crianças das escolas premiadas e das escolas apoiadas sobre como ensinam suas professoras:

Ela explica, ela fala os gêneros, os textos, aí a gente lê, e eu aprendo mais [...]. Os gêneros do convite, do informativo, narrativo [...]. A professora passa tarefas [...]. Ela ensina a ler, começa com as sílabas, depois vai passando palavras, frases, depois que vem o texto [...]. Ela chama para a leitura, ensina a gente a fazer as tarefas e ensina também no caderno [...]. Ela chama para a leitura, faz perguntas do livro. (A4EP1).

Ensinando, fazendo a tarefa na lousa, nós escrevemos no caderno [...]. Aí ela pede para a gente botar o nome completo, a gente faz tudinho [...]. Ela chama para ler só às vezes. (A4EA1).

O que deu para atestar na pesquisa foi que, nas escolas premiadas, as educadoras empreendem práticas docentes diversificadas, voltadas prioritariamente para desenvolver habilidades de leitura e de escrita, inclusive com ênfase nos gêneros textuais. Nas escolas apoiadas, por seu turno, as professoras fazem uso predominantemente da escrita no quadro para os alunos copiarem e do acompanhamento das atividades nos livros didáticos. Nas escolas nota dez de Sobral, as docentes fazem diariamente a audição da leitura com os educandos; nas escolas apoiadas de Caucaia, por sua vez, isso só ocorre em uma das instituições e por iniciativa da professora titular da sala de $2^{\circ}$ ano do ensino fundamental.

Com relação ao componente avaliação escolar, o aspecto convergente diz respeito à aplicação de provas bimestrais elaboradas nos moldes do Spaece-Alfa. Percebeu-se que tanto as escolas premiadas quanto as apoiadas ajustam e fortalecem suas práticas avaliativas internas à luz do teste padronizado de desempenho escolar do Spaece-Alfa. Entretanto, os dois estratos de escolas possuem peculiaridades no ato de avaliar.

Sobre as avaliações escolares, a educadora da escola premiada de Sobral afirmou que:

A coordenadora avalia a leitura. Tem um dia em que ela faz o diagnóstico de leitura. Ela chama para a sala dela pela lista. No momento em que estou lendo com eles, ela fica chamando também os alunos pela lista, um por um. Lá ela tem um formulário para preencher sobre o nível de leitura de cada aluno. Ela vai ver a questão da precisão da leitura, dos erros, das palavras erradas que a criança falou. Essa é a avaliação de leitura [...]. A gente trabalha os pontos de compreensão, entonação, ritmo, velocidade em que eles leem [...], porque tudo isso que ela faz é conforme a avaliação da prefeitura, porque os meninos vão ter que passar pela avaliação da prefeitura. Depois que o aluno lê, ela faz perguntinhas para ver a compreensão da criança. (P5EP1). 
Nessa perspectiva, as escolas nota dez de Sobral avaliam em três vertentes: aferem o nível de leitura do aluno, avaliando a quantidade de palavras lidas, a entonação, a velocidade, o ritmo, a precisão e a compreensão textual; realizam, a cada 15 dias, provas de produção escrita e corrigem por meio de uma chave de correção, avaliando ortografia, pontuação, paragrafação, coesão e coerência; e aplicam a prova bimestral elaborada pela coordenação escolar. Essas vertentes espelham-se nos descritores que serão avaliados pelos exames externos de âmbito estadual e municipal. Inclusive, as escolas premiadas costumam ensaiar antecipadamente a ritualística do dia da aplicação das avaliações externas, simulando a experiência com as crianças.

Nessa esteira, conforme Freitas (2014), entende-se que as crianças são geralmente pressionadas a responderem a um ritmo, a uma velocidade e a uma habilidade de leitura padrão designados pelos testes padronizados. Vislumbra-se o mecanismo de controle mais uma vez presente nas escolas nota dez de Sobral, agora com o mapa de acompanhamento das habilidades de leitura exposto em cada sala de aula.

As escolas apoiadas de Caucaia praticam avaliações somativas, ao final de cada bimestre, e formativas, com aplicação de atividades diversificadas que envolvem pesquisas, cópias, trabalhos escolares, além de levarem em conta o comportamento, a frequência e a participação dos estudantes nas atividades escolares. As escolas apoiadas atribuem valor às atitudes comportamentais dos educandos, como afirma o depoimento abaixo:

No caso do $2^{\circ}$ ano, primeiro faço a parte de leitura, aplico ditado para ver o nível da escrita. [...] Por bimestre, tem três notas: nota 1 - trabalhos, pesquisas, apresentações; nota 2 - são critérios como: comportamento, pontualidade, frequência, tarefa de casa, tarefa de classe, participação, tomada de leitura, produção textual; se for Matemática, tem raciocínio lógico. Para cada critério, vale um pontinho; nota 3 - prova escrita. A média é 5,0. (P2EA2).

Portanto, notou-se que a avaliação escolar das escolas apoiadas de Caucaia não se encontra subordinada por completo aos padrões e aos objetivos das avaliações externas, como acontece com as escolas premiadas.

\section{SÍNTESE CONCLUSIVA}

A partir da fusão de horizontes, concluiu-se que as dinâmicas pedagógicos das escolas premiadas de Sobral e das apoiadas de Caucaia são reorientados pelo teste padronizado do SpaeceAlfa, direcionando o currículo, a metodologia e o propósito do processo de ensino aprendizagem, ou seja, sobredeterminando os trabalhos docentes. Contudo, observou-se que, em Sobral, esses 
procedimentos são mais bem elaborados, sistematizados e monitorados, incidindo determinantemente sobre o conteúdo curricular a ser ensinado e sobre a maneira como devem ser trabalhados na escola, objetivando que os estudantes alcancem os melhores resultados.

$\mathrm{Na}$ sequência, verificou-se que as escolas cearenses, em busca de atingirem o status de Escolas Nota Dez, acabam estimulando a aprendizagem memorística e reprodutivista dos conteúdos com vista a conquistar metas e alcançar resultados. Essa reação escolar, como adverte Araújo (2016), baseia-se nos princípios da meritocracia, do tecnicismo e da produtividade.

O Prêmio Escola Nota Dez, por ser uma política que usa a avaliação externa para responsabilizar fortemente os atores educacionais pelos resultados escolares, devido à bonificação escolar, tende, por um lado, a estimular e a provocar mudanças positivas no trabalho docente; por outro lado, tende a pressionar o corpo docente a alcançar as metas, causando tensões e desgastes nas relações intra e interpessoais no contexto escolar.

Por fim, comprovou-se que o Prêmio Escola Nota Dez vem fomentando alterações na práxis docente e, por conseguinte, afetando as práticas pedagógicos das escolas premiadas de Sobral e das apoiadas de Caucaia. Contudo, faz-se mister lembrar que não se pretende aqui generalizar tais resultados, haja vista que a amostra da pesquisa não representa o universo das escolas estaduais do Ceará. Portanto, novos estudos são necessários para comprovar o impacto dessa política e de seus diferentes desenhos, tanto no desempenho quanto nas práticas de gestão pedagógica e escolar. 


\section{REFERENCIAS}

AFONSO, A. J. Políticas avaliativas e accountability em educação. Subsídios para um debate ibero-americano. Sísifo: Revista de Ciências de Educação, Lisboa, v. 9, p. 57-70, 2009.

ARAÚJO, K. H. Os efeitos do Prêmio Escola Nota Dez nos processos pedagógicos das escolas premiadas de Sobral e das apoiadas de Caucaia no ano de 2009. 2016. 185f. - Dissertação (Mestrado em Educação) Universidade Federal do Ceará, Programa de Pós-graduação em Educação Brasileira, Fortaleza (CE), 2016.

BONAMINO, A.; SOUZA, S. K. Três gerações de avaliação da educação básica no Brasil. Educação e Pesquisa, São Paulo, v. 38, n. 2, p. 373-388, 2012.

BRASIL. IBGE. Censo Demográfico, 2010. Disponível em:<https://cidades.ibge.gov.br/brasil/ce/sobral/panorama $>$. Acesso em 06 de abril 2018b.

Ministério da Educação. Instituto Nacional de Estudos e Pesquisas Educacionais Anísio Teixeira. Características do Saeb. 2011a. Disponível em: colocar a referência. Acesso em: 10 jul. 2017.

Ministério da Educação. Instituto Nacional de Estudos e Pesquisas Educacionais Anísio Teixeira (INEP). Censo Escolar 2010. Brasília, DF: INEP, 2011b.

BROOKE, N.; CUNHA, M. A. A avaliação externa como instrumento da gestão educacional nos estados. Estudos e Pesquisas Educacionais, São Paulo, v. 2, p. 17-79, 2011.

BROOKE, N.; CUNHA, M. A.; FALEIROS, M. A avaliação externa como instrumento da gestão educacional nos estados: relatório final. Minas Gerais: GAME/FAE/UFMG: Fundação Victor Civita, ago. 2011.

CALDERÓN, A. I.; RAQUEL, B. M. G.; CABRAL, E. S. O Prêmio Escola Nota 10: meritocracia e cooperação para melhoria do desempenho escolar. Ensaio: Avaliação em Políticas Públicas em Educação, Rio de Janeiro, v. 23, n. 87, p. 517-540, 2015.

CARNEIRO, D.; IRFFI, G. Política de incentivos à escola melhora a proficiência no ensino fundamental? Uma avaliação do Prêmio Escola Nota Dez. In: ENCONTRO DE ECONOMIA DO CEARÁ EM DEBATE. 10., 2014, Fortaleza. Anais... Fortaleza: Ipece, 2014.

CASTro, M. H. G. Sistemas de avaliação da educação no Brasil: avanços e novos desafios. São Paulo Perspectiva, São Paulo, v.23, n.1, p. 5-18, 2009.

CEARÁ. Secretaria da Educação do Governo do Ceará. Gráfico Maurício Holanda Maia. Disponível em: <http://pt.brau del.org br/eventos/arquivos/downloads/mauricio-holanda-maia.pdf>. Acesso em: 14 jun. 2017.

Secretaria da Educação do Ceará. SPAECE-Alfa-2013. Boletim Pedagógico - Língua Portuguesa $-2^{\circ}$ ano do Ensino Fundamental. Juiz de Fora: CAEd, 2013c.

Lei 13.203, de 21 de fevereiro de 2002. Institui o prêmio educacional "Escola do Novo Milênio - Educação Básica de Qualidade no Ceará”, relativo ao ano de 2001, e dá outras providências. Diário Oficial do Estado, Fortaleza, 25 fev. 2002. Série 2, ano V, n. 37, p. 48-49.

Lei 15.923, de 15 de dezembro de 2015, regulamentada pelo Decreto 32.079, de 9 de novembro de 2016. Modifica a Lei Estadual 15.052, de 6 de dezembro de 2011, que define premiação para as escolas públicas de $2^{\circ}, 5^{\circ}$ e $9^{\circ}$ anos do Ensino Fundamental com os melhores resultados na avaliação do Spaece, bem como apoio financeiro às escolas de $5^{\circ}$ e $9^{\circ}$ ano com os menores resultados nesta avaliação. Diário Oficial do Estado do Ceará, Fortaleza, 16 dez. $2015 b$.

FERNANDES, R. Índice de Desenvolvimento da Educação (Ideb). Brasília, DF: MEC/INEP, 2007. (Série Textos para Discussão, 26).

FERNANDES, R.; GREMAUD, A.P. Qualidade da educação: avaliação, indicadores e metas. In: VELOSO, F. et al. (Org.). Educação básica no Brasil: construindo o país do futuro. Rio de Janeiro: Elsevier, 2009. p. 213-238.

FREITAS, L.C. Os reformadores empresariais da educação e a disputa pelo controle do processo pedagógico na escola. Educação e Sociedade, Campinas, v. 35, n. 129, p. 1085-1114, 2014.

GADAMER, H.G. Verdade e método: traços fundamentais de uma hermenêutica filosófica. 3. ed. Petrópolis: Vozes, 1997. 
NETO, J.L.H. Avaliações educacionais e seus reflexos em ações federais e na mídia eletrônica. Estudos em Avaliação Educacional, São Paulo, v. 25, n. 59, p. 172-201, 2014.

SEDUC. Spaece: o programa. Fortaleza: Seduc, 2008. Disponível em:<http://www.seduc.ce.gov.br/index.php/88pagina-inicial-servicos/avaliacao-educacional/5170-spaece>.Acesso em: 29 dez. 2017.

SCHMIDT, L.K. Hermenêutica. 2. ed. Petrópolis: Vozes, 2013. 


\section{RESUMO}

O artigo analisa os efeitos da política accountability educacional, representada pelo Prêmio Escola Nota Dez nas dinâmicas pedagógicas das escolas cearenses. Utilizou-se a abordagem qualitativa, empregando-se, como procedimentos, a pesquisa bibliográfica e a de campo. Foram realizadas entrevistas semiestruturadas aos representantes do núcleo gestor escolar, aos professores e aos alunos do $2^{\circ}$ ano do ensino fundamental, em quatro instituições de ensino. Concluiu-se que as dinâmicas escolares são reorientadas pelo Sistema Permanente de Avaliação da Educação Básica do Ceará - Alfa, direcionando o que, como e para que ensinar. Verificou-se que a prática de bonificação tende a pressionar o corpo docente a alcançar as metas, causando tensões nas relações intra e interpessoais no contexto escolar.

Palavras-chave: Prêmio Escola Nota Dez. Accountability. Dinâmicas pedagógicas.

\section{EDUCATIONAL ACCOUNTABILITY POLICY IN THE STATE OF CEARÁ: REPERCUSSIONS IN PEDAGOGICAL DYNAMICS}

\section{ABSTRACT}

The paper analyzes the effects of educational accountability policy, represented by the School Note Ten Award in the educational dynamics of schools in Ceará. The qualitative approach was used, using bibliographic and field research as procedures. Semi-structured interviews were carried out with representatives of the school managements, teachers and students at second year of elementary education in four educational institutions. Were concluded that the school dynamics are reoriented by the Permanent System of Evaluation of Basic Education of Ceará - Alfa, directing what, how and what to teach. This practice tends to pressure the teaching staff to reach the goals, causing tensions in the intrapersonal and interpersonal relationships in the school context.

Keywords: Note Ten School Award. Accountability. Pedagogical dynamics.

\section{POLÍTICA ACCOUNTABILITY EDUCACIONAL EN EL ESTADO DEL CEARÁ: REPERCUSIONES EN LAS DINÁMICAS PEDAGÓGICAS}

\section{RESUMEN}

El artículo analiza los efectos de la política accountability educativa, representada por el Premio Escuela Nota Diez en las dinámicas pedagógicas de las escuelas cearenses. Se utilizó el abordaje cualitativo, empleándose, como procedimientos, la investigación bibliográfica y la de campo. Se realizaron entrevistas semiestructuradas a los representantes del núcleo gestor escolar, a los profesores ya los alumnos del $2^{\circ}$ año de la enseñanza fundamental, en cuatro instituciones de enseñanza. Se concluyó que las dinámicas escolares son reorientadas por el Sistema Permanente de Evaluación de la Educación Básica de Ceará - Alfa, dirigiendo lo que, cómo y para que enseñar. Se verificó que la práctica de bonificación tiende a presionar al cuerpo docente a alcanzar las metas, causando tensiones en las relaciones intra e interpersonales en el contexto escolar.

Palabras-clave: Premio Escuela Nota Diez. Accountability. Dinámicas pedagógicas. 